\title{
Meet the new Editor-in-Chief
}

Prof. C.J. Carrano, San Diego State University, is the new Editor-in-Chief of the journal BioMetals. Carl takes over as of September 1, 2020 from long time Editor-in-Chief Prof. Dr. Günther Winkelmann. Carl, an inorganic chemist by training, has extensive experience in elucidating the function and roles of inorganic trace elements in biological systems. He received his BS in Chemistry from UC Santa Barbara in 1972, his PhD from Texas A\&M in 1976 and did postdoctoral work at UC Berkeley from 1976 to 1979. He has $40+$ years of academic experience at the University of Vermont, Texas State University and
San Diego State University including $20+$ years as Department Head at the latter two institutions. He is the author of over 180 peer reviewed publications, is an Associate Editor of the journal Molecules, and was honoured by being elected as a Fellow in Chemistry by the AAAS in 2011, the Royal Society of Chemistry in 2016 and the Hanse-Wissenschaftskolleg (Institute for Advanced Study, HWK) in 2019.

Publisher's Note Springer Nature remains neutral with regard to jurisdictional claims in published maps and institutional affiliations. 